\title{
Functional Integrity of NMDA-dependent LTP Induction Mechanisms Across the Lifespan of F-344 Rats
}

\author{
Carol A. Barnes, ${ }^{1,2,4,5}$ Geeta Rao, ${ }^{4}$ and Bruce L. McNaughton ${ }^{1,3,4}$ \\ Departments of ${ }^{1}$ Psychology, ${ }^{2}$ Neurology, and ${ }^{3}$ Physiology and \\ ${ }^{4}$ Arizona Research Laboratories Division of Neural Systems, Memory, and Aging \\ University of Arizona \\ Tucson, Arizona 85724
}

\section{Abstract}

Previous studies have reported a lack of an age effect in the induction of long-term potentiation (LTP) at CA1 synapses, using robust (supramaximal) stimulation parameters, but an apparent age effect on the induction threshold of LTP using less robust stimulation, in the perithreshold region. These findings have led to the suggestion that old animals may experience an alteration either in the efficacy of activation of $\boldsymbol{N}$-methyl-D-aspartate (NMDA) receptors or in the metabolic processes subsequent to NMDA receptor activation that lead to LTP expression. An alternative explanation for the apparent threshold change in old animals is that, because of the known reduction of the intracellularly recorded, compound EPSP magnitude in old rats, equivalent electrical stimulation results in a smaller effective depolarization of the postsynaptic cells and a consequently less effective activation of NMDA receptors, which are otherwise functionally normal. To distinguish between these two hypotheses, weak orthodromic stimulation was paired with intracellularly applied current pulses, thus holding constant the degree of postsynaptic depolarization. No differences in LTP induction threshold or magnitude were observed in a large sample of rats from three age groups. It is concluded that the NMDA receptor mechanisms and associated biochemical processes leading to LTP induction are not

${ }^{5}$ Corresponding author. altered in aged F-344 rats. The reduced compound EPSP in old animals was reconfirmed in the present study, and a significant correlation was found in old rats between the magnitude of the EPSP at a fixed stimulus level and their performance on a spatial memory task.

\section{Introduction}

Learning and memory deficits occur during the normal course of aging (e.g., Albert 1988; de Toledo-Morrell et al. 1988; Landfield 1988; Barnes 1990; Rapp and Amaral 1992; Craik et al. 1995; Petersen 1995; Zyzak et al. 1995). Because the hippocampus appears to play a crucial role in memory (e.g., O'Keefe and Nadel 1978; Squire 1992; Cohen and Eichenbaum 1993), changes in this structure during aging have been prime suspects in the etiology of age-related memory impairment. For example, specific electrophysiological (e.g., Landfield and Lynch 1977; Barnes 1979; Reynolds and Carlen 1989; Barnes et al. 1992; Moyer et al. 1992; Papatheodoropoulos and Kostopoulos 1996; Thibault and Landfield 1996), neurochemical (e.g., Meaney et al. 1988; Gallagher et al. 1990; Gribkoff and Bauman 1992; Potier et al. 1992; Taylor and Griffith 1993), and morphological (e.g., Landfield et al. 1977; Geinisman et al. 1995) alterations have been demonstrated to occur in an age-dependent fashion in the hippocampus. Furthermore, a number of significant correlations have been reported between such neurobiological alterations and the behavioral expression of hippocampal-dependent mnemonic processing (e.g., Barnes 1979; Geinisman et al. 1986a,b, 1992; Pelleymounter et al. 1990; Castorina et al. 1993; Scheuer et al. 1995; Thibault and Landfield 1996).

LEARNING \& MEMORY 3:124-137 (C) 1996 by Cold Spring Harbor Laboratory Press ISSN1072-0502/96 \$5.00

$$
\begin{array}{llllllllllllllll}
\hline & E & A & R & N & I & N & G & \begin{array}{l}
\text { 女 } \\
124
\end{array} & M & E & M & O & R & Y
\end{array}
$$


Although it is clear that age-related changes in specific aspects of hippocampal neurobiology occur, it is equally clear that the process of aging is not one of generalized deterioration. Many aspects of hippocampal neuronal function remain unaltered throughout the lifespan (e.g., Barnes 1994), and quantitative analysis of those characteristics that are altered and those that are preserved is an important prerequisite to the possible development of therapeutic or prophylactic strategies (e.g., Gallagher et al. 1985; Straube et al. 1990; Davis et al. 1993; Baxter et al. 1994; Müller et al. 1994; Stone et al. 1994; Ingram et al. 1996).

One form of hippocampal plasticity consistently found to be intact in old, memory-deficient rats is the induction of hippocampal long-term potentiation or enhancement (LTP; Bliss and Lømo 1973) at the Schaffer collateral-CA1 pyramidal cell synapse (Landfield and Lynch 1977; Landfield et al. 1978) and at the perforant path-granule cell synapse (Barnes 1979; de Toledo-Morrell et al. 1988 ). Both young and old rats show similar relative levels of synaptic enhancement following LTP-inducing stimulation under protocols that involve stimulus intensities well above the threshold for LTP induction. On the other hand, the maintenance of LTP at the perforant path-granule cell synapse is deficient in old rats, when responses are monitored over days or weeks in chronic preparations (Barnes 1979; Barnes and McNaughton 1980b; de Toledo-Morrell et al. 1988). Old rats show LTP decay rates of approximately twice that of young rats, and this maintenance deficit is correlated with faster forgetting of spatial behavioral tasks (Barnes and McNaughton 1985). What mechanisms may be responsible for this faster LTP decay in old animals is a question of active interest and has yet to be resolved (e.g., Shahi and Baudry 1993; Worley et al. 1993; Barnes et al. 1994; Casoli et al. 1996).

Although there is near universal acceptance that LTP induction is intact following suprathreshold stimulus induction protocols in old rats (Landfield and Lynch 1977; Landfield et al. 1978; Barnes 1979; Barnes and McNaughton 1980b; de ToledoMorrell et al. 1988; Deupree et al. 1991; Moore et al. 1993; but see Tielen et al. 1983; Hori et al. 1992; Lynch and Voss 1994), several recent experiments have suggested that the LTP induction threshold itself may change with age. In CA1, age deficits in LTP induction have been observed when less robust, perithreshold stimulation parameters were used [e.g., 4 pulses at $100 \mathrm{~Hz}$ (De- upree et al. 1991), 10 pulses at $100 \mathrm{~Hz}$ (Deupree et al. 1993), and primed burst stimulation consisting of a single priming pulse followed $170 \mathrm{msec}$ later by 4 pulses at $200 \mathrm{~Hz}$ (Moore et al. 1993)]. Assuming that the LTP process observed under conditions of artificial, massively synchronous stimulation reflects processes normally used by the hippocampus to store information (e.g., Barnes 1995), an age-related deficit in this mechanism has important implications.

There are a number of factors that might contribute to this apparent change in LTP induction threshold. Two of these are addressed in the present report: (1) possible age-related differences in $N$-methyl-D-aspartate (NMDA) receptormediated events leading to LTP induction and (2) age-related differences in the magnitude of stimulus-evoked synaptic potentials in CA1, which may be attributable to a reduced synapse density in old rats (Barnes et al. 1992). A change in the effective input for a fixed stimulus level would be expected to result in reduced input cooperativity (McNaughton et al. 1978) and hence could result in an apparent change in LTP threshold in the absence of any functional alterations at individual synapses. Barnes et al. (1992) conducted minimal stimulation (McNaughton et al. 1981) experiments in CA1 and found that the reduced population EPSP in old animals was not accompanied by a change in either the "unitary EPSP" (the intracellularly recorded EPSP elicited by stimulation of single afferents) or the apparent quantal magnitude as assessed by conventional statistical methods of quantal analysis. Thus, the reduced EPSP in old rats is most likely attributable to a reduction in the number of synapses activated by a given stimulus. This conclusion is somewhat at variance with that of Gribkoff and colleagues (Bauman et al. 1992; Gribkoff and Bauman 1992) who attributed the reduced EPSP in old rats to a tonic increase of adenosinergic inhibition. This explanation appears unlikely, however, because the adenosine effects on EPSP magnitude are known to be presynaptic and are associated with a change in quantal release probability and consequent alteration of paired pulse facilitation ratios (Lupica et al. 1992). Neither quantal release probability nor paired pulse facilitation are altered in CA1 of old rats (Landfield and Lynch 1977; Landfield et al. 1978; Barnes et al. 1992; Deupree et al. 1993).

The pivotal role that the NMDA receptor plays in LTP induction (e.g., Collingridge 1987) makes NMDA receptor-mediated glutamatergic transmis-

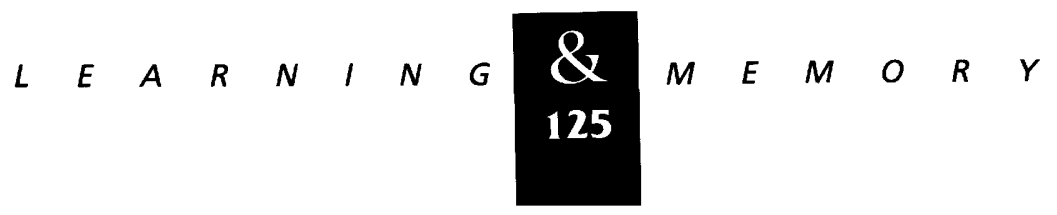


sion an obvious target for investigation of age-related defects in the LTP process. Unfortunately, the study of age differences in hippocampal NMDA receptors has yielded conflicting results. Depending on the experimental methods, NMDA receptor-binding studies have yielded apparent age-related increases (Baudry et al. 1981), decreases (Fiore and Rampello 1989; Bonhaus et al. 1990; Pelleymounter et al. 1990; Tamaru et al. 1991; Wenk et al. 1991; Clark et al. 1992; Cohen and Müller 1992; Ingram et al. 1992; Ogawa et al. 1992; Castorina et al. 1993; Cimino et al. 1993; Magnusson and Cotman 1993), or equivalence (Kito et al. 1990; Kusztos et al. 1996; Magnusson 1996; Shimada et al. 1996). The reasons for these apparently discrepant findings most likely include differences in assay conditions, specificity of ligands used, and type of recognition site assessed (e.g., Ingram et al. 1996; Magnusson 1996). Furthermore, because measures of receptor binding are made relative to total protein content, it is not possible to draw clear conclusions about how such NMDA binding changes might translate into changes at the level of individual synapses or neurons. The fact that the magnitude of LTP in young and old rats can be identical following robust stimulation suggests that NMDA receptor-mediated events can work properly at old hippocampal synapses under some conditions; however, the nearthreshold stimulation protocols in which LTP induction deficits are observed may unmask an underlying deficit in NMDA receptor function.

On the other hand, it is possible that the NMDA receptor-mediated events leading to the induction of LTP are intact in old animals but that changes in the number or efficacy of individual synapses may result in less effective depolarization and hence less NMDA receptor activation for a given stimulus in the old rats (Gustafsson and Wigström 1986; Gustafsson et al. 1987; Malenka 1991; Yoshioka and Sakurai 1995). Such an effect would be nonlinear, affecting the apparent threshold for induction more than the asymptotic level of LTP obtained with strong stimulation. This is a plausible explanation, considering that, in the perithreshold stimulation studies in which LTP deficits were observed, similar stimulus intensities were used in the young and old animals. It is known that for a given intensity, orthodromic stimulation of Schaffer collateral afferents results in smaller excitatory postsynaptic potentials in old rats (Landfield et al. 1986; Barnes et al. 1992; Bauman et al. 1992; Gribkoff and Bauman 1992; Rao et al. 1993; Papatheodoropoulus and Kostopoulos 1996), whereas there is no detectable change in the amplitude or threshold of the Schaffer collateral presynaptic fiber potential in vitro (Barnes et al. 1992) or in vivo (Rao et al. 1996). Although not definitive, a constellation of electrophysiological findings suggests that this reduction in the population EPSP is a consequence of a reduction in the number of Schaffer collateral synaptic contacts in old rats without changes in the efficacy of the remaining synapses. Although this conclusion requires verification by synapse counts in CA1 obtained with unbiased stereological methods (cf. Scheff et al. 1985; Geinisman et al. 1995), the fact remains that the population EPSP in old animals is smaller for a given input stimulus. This leads to a question as to the origin of the reported elevation of the LTP induction threshold in old age.

To avoid the potential confounds that can arise when LTP is induced by the cooperativity method (i.e., orthodromic stimulation), we have used an LTP induction paradigm that directly depolarizes the postsynaptic cell. With this method, LTP is induced by repeatedly pairing a weak orthodromic stimulus with intracellular depolarizing current injection (Wigström et al. 1986; Gustafsson et al. 1987; Lin et al. 1993). The advantage of the "paired-depolarization" current injection method in characterizing age changes in synaptic plasticity is that the depolarization level of the cell is under experimental control. This allows the assessment of the ability of NMDA receptors to induce LTP when the level of depolarization is essentially independent of the number of synapses activated. The paired depolarization method was used here to induce LTP in F-344 rats of three ages, who were screened, prior to sacrifice, on a hippocampal-dependent spatial memory test. Some of these data have been presented in abstract form (Rao et al. 1995).

\section{Materials and Methods}

Three age groups of F-344 male rats were used in this experiment. The pups $(n=30 ; 21-35$ days old) were obtained from Charles River Laboratories (Wilmington, MA). Nine-month-old ( $n=34$ retired breeders) and 24- to 28-month-old ( $n=15$ virgin; $n=19$ retired breeders) rats came from the National Institute on Aging colony at Harlan Sprague-Dawley (Indianapolis, IN). Virgin old rats 
were used when retired breeders were not available in sufficient quantities from this breeding facility. The rats were singly housed in Plexiglas guinea pig tubs with free access to food and maintained on a 12-hr/12-hr light-dark cycle.

\section{BEHAVIORAL TESTING}

All rats were handled upon arrival for at least the week prior to behavioral testing. Rats were tested in the Morris swim task for assessment of spatial and visual discrimination learning ability prior to sacrifice. A circular tank $(120-\mathrm{cm}$ diam., $36-\mathrm{cm}$ depth) was partially filled with water (26$28^{\circ} \mathrm{C}$ ) made opaque by adding white, nontoxic, Crayola paint. A variety of visual stimuli (e.g., pictures, light sources, and a bookcase) in the $2.3 \times 2.7 \times 2.5-\mathrm{m}$ room were available as distal cues; more proximal cues consisted primarily of a chair and a metal board located near the wall of the pool (and see below for additional cues in the visual discrimination version). For the spatial version of the swim task, a circular escape platform $(11.5 \mathrm{~cm}$ diam.) was present in a constant location in the northwest quadrant of the tank, submerged $\sim 1 \mathrm{~cm}$ below the water surface. For the cue, or visual, discrimination version of the task, the platform was moved randomly to one of four locations in the tank after each trial. For this condition, the platform extended $2 \mathrm{~cm}$ above the water level. To enhance its visibility, a band of black electrical tape was wrapped around the portion of the platform extending above water level and a piece of cardboard was hung directly overhead. A black piece of duct tape was attached to the back of each rat during training to enable position tracking by an overhead video camera connected to a VP114 tracking unit (HVS Image, England). The rat's swim path during the trial was reconstructed as a series of $x-y$ coordinates acquired and analyzed using custom software (TR, J. Forster; WMAZE, M. Williams).

During the spatial task, each rat was given three blocks of 2 training trials per day for 4 days (24 trials total). During the interblock intervals, rats were placed into a heat-controlled incubator (Ohio Medical Products, Air Reduction Co., Inc.) as old rats are particularly vulnerable to hypothermia in this task (Lindner and Gribkoff 1991). At the start of each trial, the rat was released into the water, facing the tank wall, from one of seven peripherally located, evenly spaced points. The re- lease location varied pseudorandomly from trial to trial (no two trials within the same block were from the same location). When the rat located the escape platform or swam for a maximum of $60 \mathrm{sec}$, it was allowed to sit on the platform for $30 \mathrm{sec}$. At the end of the fourth day of training, the hidden platform was removed for a single probe trial in which the rat was allowed to swim in the pool freely for $60 \mathrm{sec}$. The following day, the rat was given six trials on the visible platform, cue discrimination task, with both the release location and platform location randomized from trial to trial. To assess performance on the spatial and cued versions of the task, corrected integrated path length (CIPL), or the sum of the distances from the target throughout the trial, was calculated from total distance and latency measures on each trial. This measure incorporates a correction factor to compensate for differences in distance to the goal from the various start locations at the side of the pool (for details, see Gallagher et al. 1993). For analysis of the 60-sec swim during the probe trial, the average distance from the target (AD), the number of target crossings (crossings over the area previously occupied by the platform), and search time in each quadrant were calculated. Animals that were poor at the cue task, because of thigmotaxis or to poor swimming ability, were excluded from the experiment.

\section{ELECTROPHYSIOLOGY}

Because of the time-consuming nature of these experiments, only one rat was sliced per day; however, in any given week, at least one animal from each of the three age groups was tested to control for variability because of changing chamber conditions. Hippocampal slices were prepared as described previously (Barnes et al. 1987). The rat was deeply anesthetized with Metofane (Pitman-Moore) and decapitated. Tissue sections were cut $(450 \mu \mathrm{m})$ parallel to the alveus using a tissue chopper and were then transferred to an interface-style brain slice chamber (Haas et al. 1979) perfused with artificial cerebrospinal fluid (ACSF) at $2.0 \mathrm{ml} / \mathrm{min}$. The ACSF consisted of the following in $\mathrm{mm}$ (after Gustafsson et al. 1987): $\mathrm{NaCl}, 124 ; \mathrm{CaCl}_{2}, 4 ; \mathrm{KCl}, 4 ; \mathrm{MgCl}_{2}, 4 ; \mathrm{NaHCO}_{3}, 26$; dextrose, 10 ( $\mathrm{pH} 7.4)$. A knife cut was made with a scalpel blade between the CA3/CA1 regions in each slice to minimize spontaneous input activity from CA3. The slices were oxygenated with a 95\%

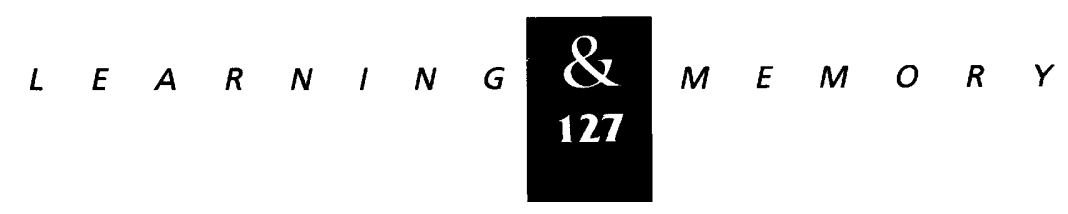


$\mathrm{O}_{2} / 5 \% \mathrm{CO}_{2}$ gas mixture, and the bath temperature was maintained at $32 \pm 1^{\circ} \mathrm{C}$. Picrotoxin $(50 \mu \mathrm{M}$; Sigma) was added into the medium $1.5 \mathrm{hr}$ after slicing in order to reduce $\mathrm{GABA}_{\mathrm{A}}$ receptor-mediated inhibition during electrophysiological recording (Gustafsson et al. 1987).

After a 2-hr incubation period, intracellular recordings were obtained in CA1 stratum pyramidale with glass micropipettes (35-75 $\mathrm{M} \Omega, 3 \mathrm{M}$ potassium acetate). Acceptable cells had input resistances $>20 \mathrm{M} \Omega$ and resting membrane potentials $\geqslant 60 \mathrm{mV}$ without holding current. When the resting membrane potential had stabilized, EPSPs were evoked at a rate of $0.2 \mathrm{~Hz}$ ( $20 \mu \mathrm{A}$, biphasic pulse of $200 \mu$ sec total duration) by stimulating in stratum radiatum with a bipolar electrode consisting of a twisted pair of Teflon-coated stainless steel wires ( $76 \mu \mathrm{m}$; Fig. 1A). Baseline recordings of the EPSP were filtered $(3 \mathrm{~Hz}, 3 \mathrm{kHz}$ ), amplified 100 times, and acquired onto an 80486 computer via Workbench data acquisition software (Datawave, Inc., $\mathrm{CO}$ ). Following a 5-min baseline recording period, a series of depolarizing current pulses ranging from $0 \mathrm{nA}$ to $4 \mathrm{nA}$, in 0.2-nA steps, was delivered through the intracellular pipette (Fig. 1B). An orthodromic stimulus was delivered $25 \mathrm{msec}$ after the onset of each 100-msec current injection pulse. The delay prevented EPSP distortion because of charging of the membrane capacitance (Fig. 1C). Following the 10 pairings at each of the 21 levels of current application ( $\sim 20 \mathrm{~min}$; Fig. 1D), orthodromic stimulation at $0.2 \mathrm{~Hz}$ was continued for $45 \mathrm{~min}$ or until the intracellular recording was no longer stable. Only one data set was collected from any given slice, and a maximum of four data sets were obtained per rat.

Following the completion of these experiments, four 9-mo-old and four 25-mo-old animals (all retired breeders) were used in additional control experiments. The first control test was conducted to verify the assumption that the LTP induced by the paired-depolarization and orthodromic input required the conjunction of these two variables. The second control experiment was conducted to determine how effective NMDA receptor antagonism would be in this paired-depolarization paradigm. For experiments involving NMDA receptor blockade, $100 \mu \mathrm{M}$ D-2-amino-5amino-phosphonovaleric acid (APV; Sigma), an NMDA receptor blocker that prevents LTP induction (Collingridge et al. 1983), was added to the media following the acquisition of two control data sets in standard media.

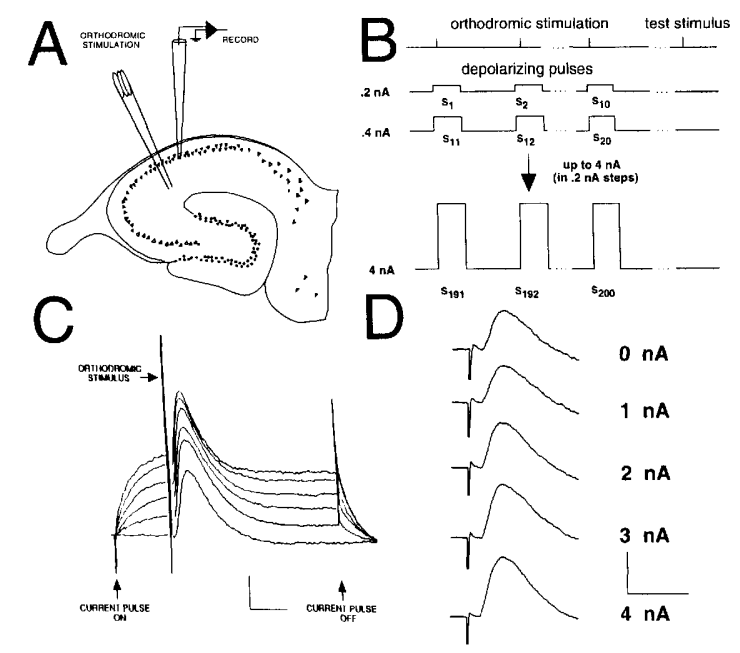

Figure 1: (A) Schematic diagram of the hippocampal slice preparation indicating the location of the orthodromic stimulating electrode in stratum radiatum and intracellular recording electrode in stratum pyramidale. $(B)$ Illustration of the paired-depolarization stimulation protocol used to induce LTP. Weak orthodromic stimuli were paired with intracellularly delivered depolarizing current pulses in steps of $0.2 \mathrm{nA}$, from 0 to $4 \mathrm{nA}$ (21 levels of current injection). Pairing was repeated 10 times at each current level, before proceeding to the next, higher level. Test stimuli were applied following each series of 10 pairings ("test stimulus") to determine the effect of the pairings (responses to test stimuli shown in D). (C) Example of the intracellular response recorded before current injection, after current onset $(100 \mathrm{msec}$ total duration), during the orthodromic stimulus (initiated 25 msec after current onset), and after current offset. Calibration bars, $3 \mathrm{mV}, 15 \mathrm{msec}$. (D) Examples of responses to test stimuli delivered in the absence of applied current following EPSP-current pairings of 0-4 nA. Note that there is less change following the lowest levels of current than following the higher levels. Calibration bars, $1 \mathrm{mV}, 10 \mathrm{msec}$.

\section{Results}

\section{SPATIAL AND VISUAL DISCRIMINATION VERSIONS OF THE MORRIS SWIM TASK}

Four old animals persisted in thigmotaxic behavior during the visible platform task. Therefore, their visual acuity could not be assessed, and their data are excluded from both the behavioral and paired-depolarization analyses presented here. Also, for the aged animals, no significant differences were found between virgins and retired breeders in any behavioral or electrophysiological parameter. Therefore, their data are collapsed in 
the following: Data from the spatial and cued versions of the Morris swim task were analyzed from 30 animals in each age group (mean age on first day of behavioral testing: pup $=27.8 \pm 1.5$ days; adult $=9.2 \pm 1.1 \mathrm{mo}$; old $=26.2 \pm 1.2 \mathrm{mo}$ ).

\section{ACQUISITION AND RETENTION OF THE SPATIAL TASK}

The CIPL was measured for each of the 24 spatial trials, and means for each block of 6 trials (each day of training) were calculated (Fig. 2A). A significant overall effect of age on CIPL was found over the 4-day spatial acquisition period $[F(2,87)$ $=20.26, P<0.0001]$, with the old animals taking a longer path to the target relative to the younger animals. Although there was no overall significant effect of age on CIPL during the first six trials $[F(2,87)=2.45, P=0.092]$, the old rats took a significantly longer path to the target than did the younger age groups on all subsequent days of the spatial training [day 2: $F(2,87)=8.18, P=0.0006$; day 3: $\quad F(2,87)=20.97, \quad P<0.0001 ;$ day 4 : $F(2,87)=19.68, P<0.0001]$. There was a significant effect of trial block on CIPL for the old animals $[F(29,3)=5.43, P<0.0018]$, indicating learning of the spatial task; however, even for the last day of training, the CIPL measure for the senescent animals was approximately twice that of the younger groups (CIPL: old $=345.8 \pm 27.9 \mathrm{~m}$; adult $=169.5 \pm 28.0 \mathrm{~m}$; pup $=132.7 \pm 20.4 \mathrm{~m}$ ), indicating that the old animals were significantly impaired in acquiring the task.

Analyses of the 60-sec probe trial (given immediately after the last spatial trial) consisted of the following parameters: search time in each quadrant, average distance from the target, and the number of target crossings. Quadrant search time data during the probe trial indicated an overall significant effect of quadrant upon search pattern $[F(3,356)=58.54, P<0.0001]$, but only the pups and adults spent significantly more time in the target quadrant than in the other three quadrants [pup: $\quad F(3,116)=73.38, \quad P<0.0001$; $\quad$ adult: $F(3,116)=31.17, P<0.0001]$. The search time in the target quadrant was significantly longer for the pups than for the adults $[F(1,58)=5.527, P=$ 0.022 ]. The old animals searched equally in all four quadrants (Fig. 2B), indicating that they had not learned the location of the target quadrant containing the platform $[F(3,116)=0.759, P=0.519]$.

Old animals also searched for the platform during the probe trial further from the target quad-
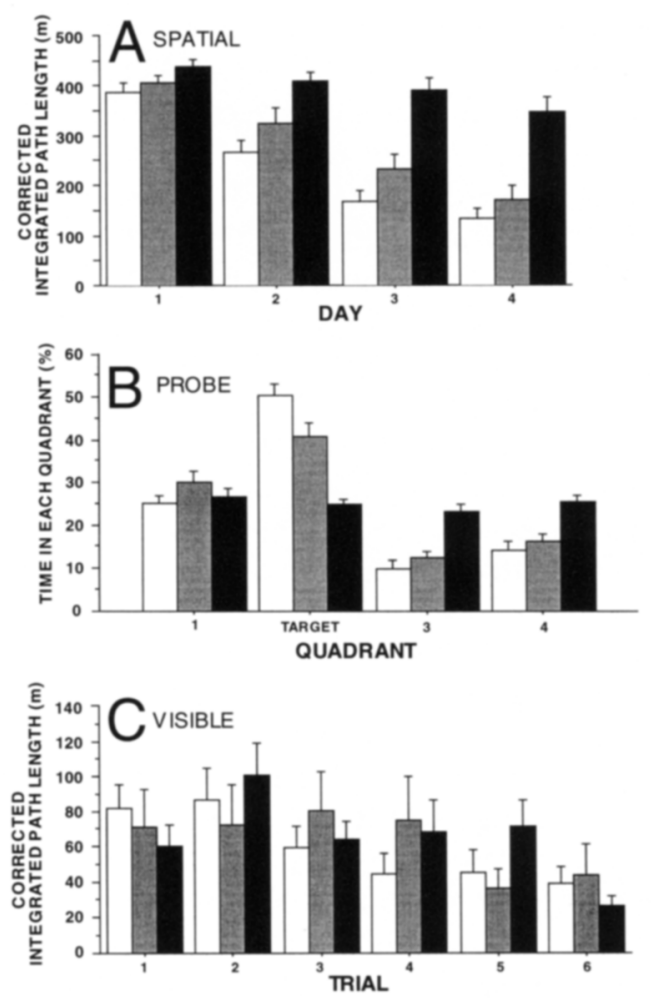

Figure 2: (A) Acquisition of the spatial version of the Morris swim task. The average of the six trials given per day was calculated for each rat, and the mean-corrected integrated path length (see Materials and Methods) is plotted for each age group $(\sim 1,9,26$ months) over the 4 days of testing ( 24 trials total). Although each group showed significant improvement over days, the old rats exhibited significantly poorer acquisition performance than did the younger two age groups. (B) A "probe" trial was given following the final spatial acquisition trial, in which the escape platform was removed, and the time spent searching in each quadrant was measured over a 60 -sec period. The two young age groups spent significantly more time searching in the quadrant in which the platform resided during training (the target quadrant) than in any other quadrant, whereas the old rats did not show this selective search pattern. Thus, these old rats exhibit impaired spatial learning. (C) To determine the extent to which visual discrimination abilities were altered across age, rats were also tested on a visible platform, cue discrimination version of the Morris swim task. Mean-corrected integrated path length is shown over the six training trials that were conducted on a single day. All groups showed improved performance over training trials, but there was no significant age effect on performance of this task, suggesting no major sensory differences between groups and equivalence of motivation. (Open bars) Pup; (shaded bars) adult; (solid bars) old.

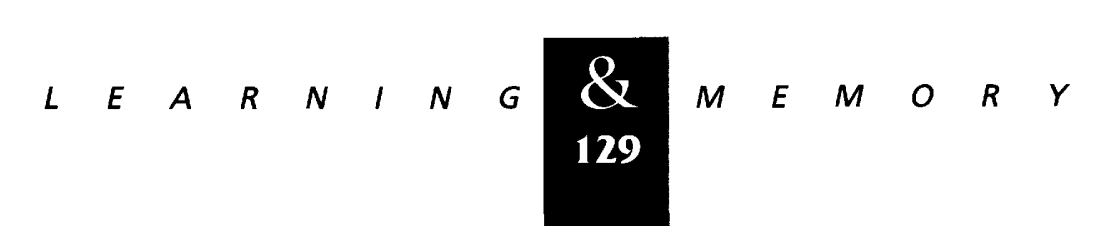


Barnes et al.

rant than did the younger rats. There was a significant effect of age on average distance [overall: $F(2,87)=16.46, P<0.0001$; AD: pup, $60.79 \pm 3.74$; adult, 67.19 \pm 3.60 ; old, 86.09 \pm 2.15 ]. There was no significant difference between the pups and the adults during the probe trial using this measure. A significant effect of age $[F(2,87)=4.58, P<0.013]$ was also observed on the number of target crossings (pup, 1.20 \pm 0.23 ; adult, 1.00 \pm 0.20 ; old, $0.43 \pm 0.09$ ), indicating a more accurate retention of the platform location for the younger age groups. Again, there was no significant difference in the values for the pup versus adult age groups $(P>0.05)$.

ACQUISITION OF THE CUE TASK

There was a significant overall effect of trial on acquisition of the visible platform version of the swim task $[F(5,534)=3.56, P<0.004]$, suggesting that the rats improved with training. There was, however, no significant effect of age [Fig. 2C; $F(2,87)=0.151, P=0.86]$, suggesting that the old rats performed as well as did the pups and adult rats on this visual discrimination problem (CIPL mean: pup, 59.50 \pm 5.52 ; adult, 63.25 \pm 8.37; old, $67.28 \pm 6.22$ ). Thus, the contribution of sensory or motivational changes to the deficits observed on the spatial problem are likely to be minimal. Furthermore, if poor performance in the spatial task was primarily because of deterioration of vision in the old rats, then a significant correlation between performance on the two versions of the swim task would be expected. This was not the case, however, as no significant relationship was found between path length on the block of six visible platform trials and the last block of spatial trials, either for the entire group of 90 animals $[F(1,88)=0.110, P=0.741]$ or within age groups.

\section{ELECTROPHYSIOLOGICAL RESULTS}

The paired-depolarization paradigm was completed in 242 CA1 pyramidal cells (pup, $n=81$; adult, $n=79$; old, $n=82$ ) in 30 rats from each age group. Consistent with previous studies (Segal 1982; Landfield and Pitler 1984; Barnes et al. 1987, 1992; Kerr et al. 1989; Potier et al. 1992, 1993; Shen and Barnes 1996), no age differences were found in basic membrane parameters in CA1 pyramidal cells, such as resting membrane potential (pup, 60.1 $\pm 1.5 \mathrm{mV}$; adult, 61.6 $2.1 \mathrm{mV}$; old, $62.8 \pm 2.0 \mathrm{mV}$ ) or input resistance (pup, 36.3 \pm 1.9 $\mathrm{M} \Omega$; adult, $31.5 \pm 1.7 \mathrm{M} \Omega$; old, $35.0 \pm 1.9 \mathrm{M} \Omega$ ).

The intracellularly recorded EPSP, elicited by a $20-\mu \mathrm{A}$ or a $60-\mu \mathrm{A}$ orthodromic stimulus in stratum radiatum, was smaller in the old rats relative to that observed in the younger age groups [20 $\mu \mathrm{A}$ : $F(2,87)=5.17, P<0.008 ; 60 \mu \mathrm{A}: F(2,87)=5.10$, $P<0.008$ ], consistent with previous data indicating smaller population Schaffer collateral-evoked EPSPs in senescent rats (Fig. 3A; Barnes et al. 1992; Rao et al. 1993). The mean EPSP amplitudes at 20 $\mu \mathrm{A}$ and $60 \mu \mathrm{A}$, respectively, were pup, $1.62 \pm 0.06$ $\mathrm{mV}, 3.29 \pm 0.13 \mathrm{mV}$; adult, $1.65 \pm 0.06 \mathrm{mV}$, $3.29 \pm 0.12 \mathrm{mV}$; old, $1.37 \pm 0.08 \mathrm{mV}, 2.76 \pm 0.15$ $\mathrm{mV}$. No significant correlation was found, how-

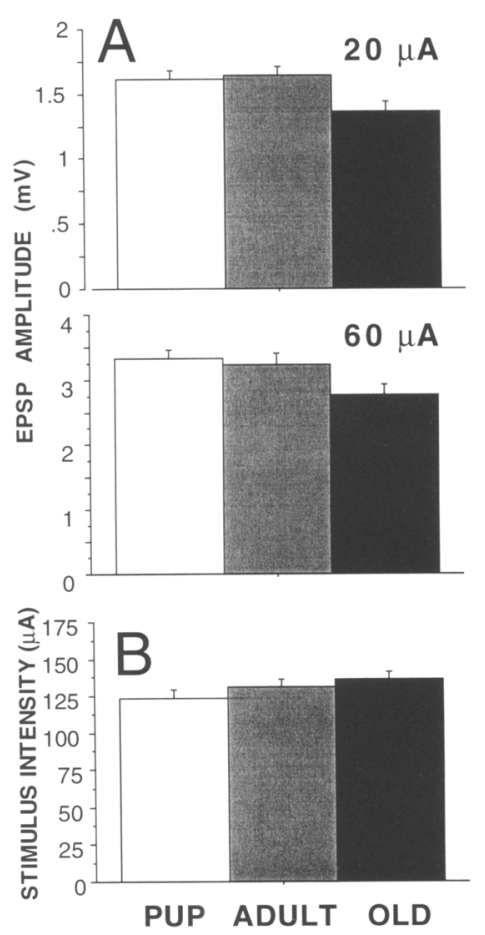

Figure 3: (A) For comparison of the present groups of animals to previous experiments, in which smaller synaptic responses have been observed following orthodromic stimulation, the synaptic responses in all rats were measured at two fixed stimulus intensity levels. The pup and adult age groups exhibited the same intracellularly recorded EPSP amplitude at the $20-\mu \mathrm{A}$ and $60-\mu \mathrm{A}$ orthodromic stimulus intensity levels, whereas the old rats showed significantly smaller compound EPSPs than the pups or adults. (B) The orthodromic stimulus intensity levels that elicited an action potential did not differ across age groups, suggesting an increase in excitability of old CA1 cells (see text). (In each age group $n=30$ rats.)

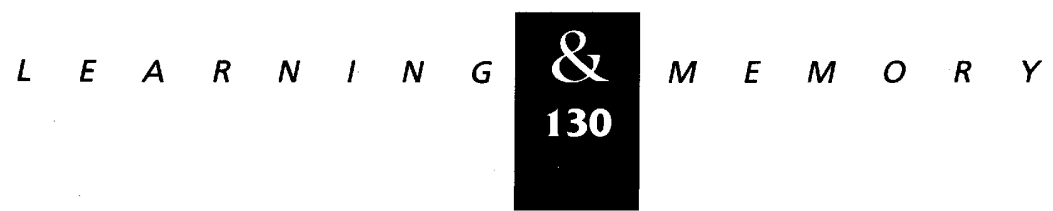


ever, between the baseline EPSP amplitude and the magnitude of LTP resulting from the current injection paradigm $[F(1,88)=0.019, P=0.891]$. In addition, no differences were found across age groups in the EPSP rise time [onset to $90 \%$ of peak; $F(2,87)=0.298, P=0.743$; mean: pup, $4.88 \pm 0.07$ msec; adult, $4.89 \pm 0.08$ msec; old, $4.82 \pm 0.06$ msec $]$ or half width $[F(2,87)=0.298, P=0.743$; mean: pup, 7.02 \pm 0.11 ; adult, $7.05 \pm 0.11 \mathrm{msec}$; old, $6.94 \pm 0.09 \mathrm{msec}$ ] measures that depend on the electrotonic characteristics of the postsynaptic neuron.

There was no significant age difference in the stimulus current required to elicit an orthodromic action potential (Fig. 3B; pup, $123 \pm 6 \mu \mathrm{A}$; adult, $131 \pm 5 \mu \mathrm{A}$; old, $136 \pm 2 \mu \mathrm{A}$ ), even though compound EPSP amplitudes were smaller in the old rats (Fig. 3A). This is consistent with previous experiments that have reported greater excitability in older animals at the Schaffer collateral CA1 synapse (Landfield et al. 1986; Barnes et al. 1987; Kerr et al. 1991; Papatheodoropoulos and Kostopoulos 1996), but it should be noted that there have been studies in which declines with age in excitability have been reported in CA1 for rats (Turner and Deupree 1991; Potier et al. 1992, 1993).

There was a statistically significant effect of paired orthodromic stimulation with current injection (Fig. 4) on the slope of the EPSP $[F(20,1869)=340.6, P<0.0001]$; however, there was no effect of age on this form of LTP induction $[F(2,1827)=0.054, P=0.9473]$. The significant
EPSP amplitude increase relative to baseline first appeared following the 0.4 -nA current injection level when the data were collapsed across age $[F(1,178)=7.17, P<0.008]$; however, this increase was not significant within age groups at the 0.4 -nA level [pup: $F(1,58)=1.66, P=0.203$; adult: $F(1,58)=3.66, \quad P=0.061 ; \quad$ old: $\quad F(1,58)=2.10$, $P=0.153$ ]. At the 0.6-nA current injection level, a highly significant increase in EPSP slope relative to baseline was present within each age group [old: $F(1,58)=25.6, P<0.0001$; adult: $F(1,58)=29.2$, $P<0.0001 ; \quad$ pup: $\quad F(1,58)=32.21, \quad P<0.0001]$. Thus, there was no age difference in the threshold for LTP induction using the paired-depolarization method. The asymptotic levels of LTP achieved with this method were $\sim 40 \%$ in each age group (LTP immediately after last pulse: pup, $41.8 \pm 2.2 \%$; adult, $42.3 \pm 2.5 \%$; old, $41.7 \pm 2.7 \%$ ) and were not significantly different across age groups $[F(2,87)=0.02, P=0.98]$. Thus, the absolute magnitude of LTP that can be induced is indistinguishable across age groups.

The increase observed in the EPSP slope following the paired-depolarization protocol persisted at least $15 \mathrm{~min}$ (Fig. 5) following the last current pulse, and this value was not different across age groups (pup, 35.6 $\pm 2.2 \%$; adult, 37.8 $\pm 2.3 \%$; old, $35.9 \pm 2.2 \%$ ). For a subset of animals, additional time points were collected out to 45 min after the last current pulse (Fig. 5). No age differences were observed in the magnitude of LTP at the 30-min (pups: $n=17,25.5 \pm 2.2 \%$;

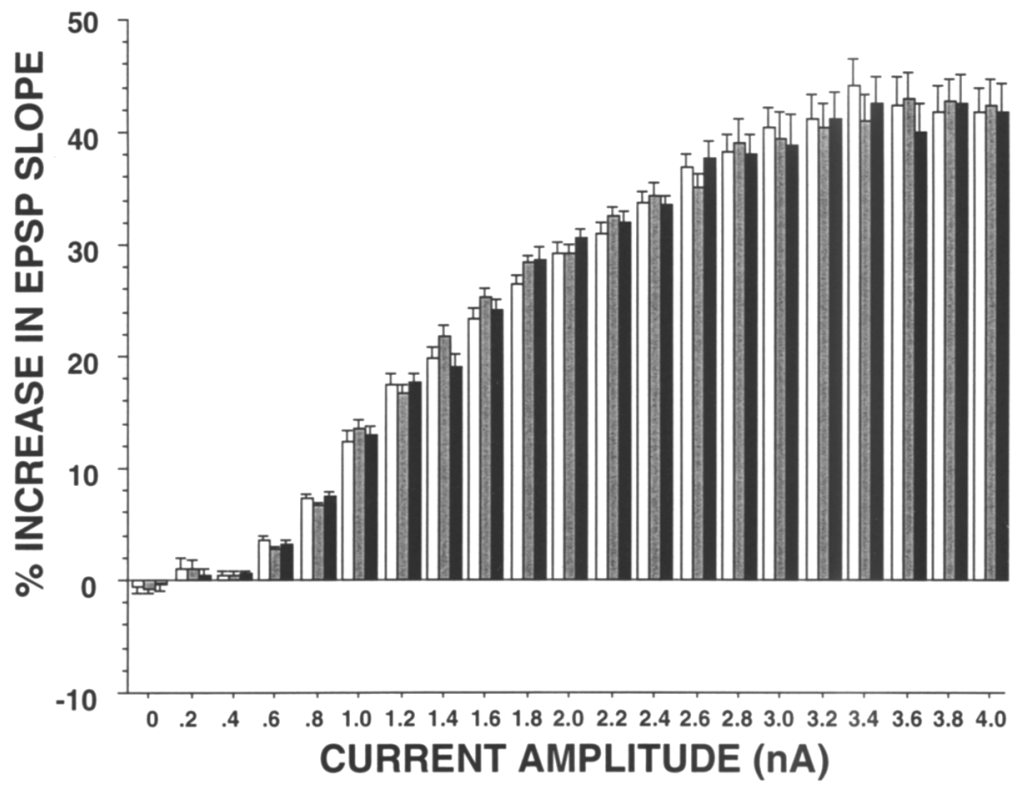

Figure 4: Mean change in EPSP slope following the paired depolarization procedure for LTP induction. Each histogram is constructed of the average of 10 pairings for each current injection level $(0-4 \mathrm{nA})$ for each rat, and when more than one data set was obtained from an animal, the average of all data sets was used for a given rat's EPSP value (i.e., the $n$ in each histogram is number of rats, which is 30 in each age group). Note that the threshold for LTP induction occurred between 0.4 and $0.6 \mathrm{nA}$ in each age group and that there is no difference between age groups in either the induction threshold or the absolute magnitude of LTP. (Open bars) Pup; (shaded bars) adult; (solid bars) old.

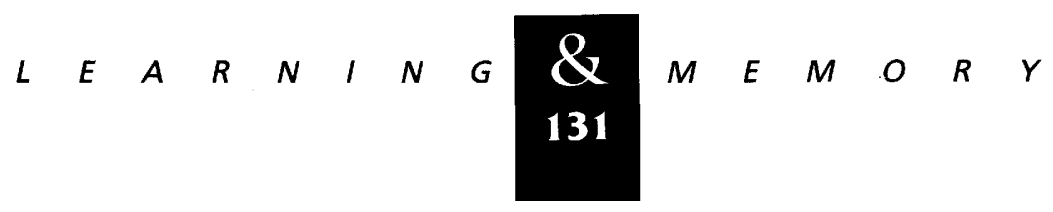




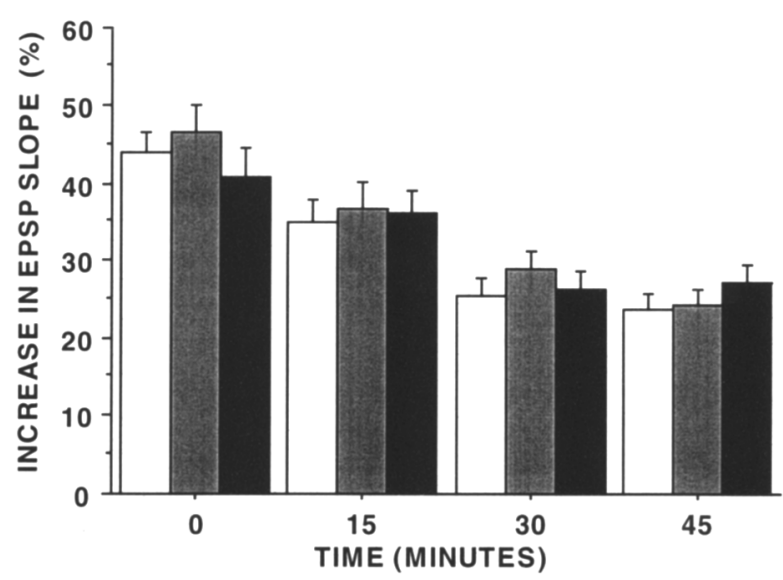

Figure 5: Persistence of pairing-induced LTP. There were no age effects on mean LTP induced following the final paired depolarization stimulus at $4 \mathrm{nA}$ (time 0 ) or at 15,30 , or $45 \mathrm{~min}$ after the final pairing. (Open bars) Pup; (shaded bars) adult; (solid bars) old.

adults: $n=17,28.9 \pm 2.9 \%$; old: $n=16,27.2 \pm$ $2.2 \%$ ) or the 45 -min time point ( $n$ as above; pup, $23.6 \pm 2.1 \%$; adult, $24.9 \pm 2.6 \%$; old, $27.2 \pm 2.2 \%$ ). Approximately the same number of cells were lost over the 45 -min time period in each age group (cells lost: pups $=47$; adults $=46$; old $=48$ ), sug. gesting that cell stability was not different between groups.

To verify the temporal dependence of orthodromic and current injection stimulation, control experiments were conducted in additional 9-month-old and 25-month-old rats. No effect of current application ( $0-4 \mathrm{nA})$ on EPSP slope was observed in either age group when the orthodromic stimulus was delivered $100 \mathrm{msec}$ [adult: $F(4,15)=0.124, P=0.972$; old: $F(4,15)=1.39$, $P=0.285$ ] or 1 sec [adult: $F(4,15)=0.178, P=$ 0.946 ; old: $F(4,15)=1.254, P=0.331]$ after the intracellular 100-msec current injection pulse had ended (Fig. 6A). Subsequent pairing of the orthodromic stimulus with the intracellular pulses in the same cells produced significant LTP of the EPSP in both age groups [adult: $F(4,15)=18.527$, $P<0.0001$; old: $F(4,15)=11.867 ; P<0.0002]$. This increase in EPSP slope remained for at least $30 \mathrm{~min}$ following the last current pulse (adult, $28.3 \% \pm 3.4$; old, $33.0 \% \pm 3.44$ ). No significant age differences were observed. These data indicate that, under these experimental conditions, conjunction of the orthodromic and depolarization pulses was required for LTP induction.

In a final set of control experiments $(n=4$

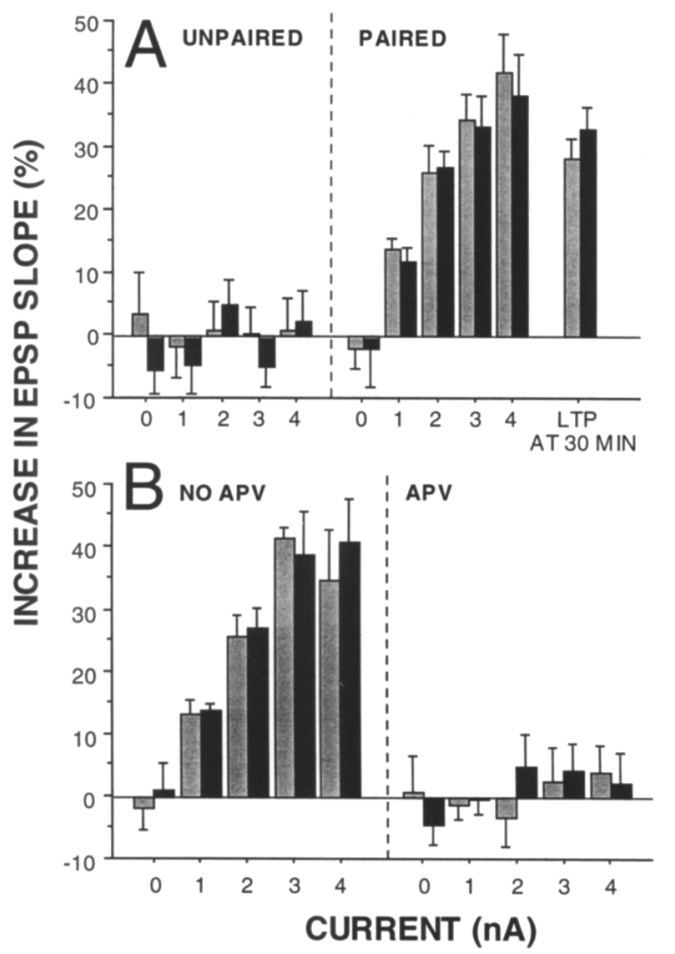

Figure 6: (A) Illustration of the control experiment conducted to verify the temporal contiguity requirement for the orthodromic stimulus and intracellular current injection. Data are shown for the case in which the current injection came $100 \mathrm{msec}$ before the orthodromic stimulus (left, unpaired), vs. the case in which they were simultaneously delivered (right, paired). No LTP was induced in the antipairing condition in either age group, whereas robust LTP, lasting at least $30 \mathrm{~min}$, was induced in the paired condition. $(B)$ Control experiment illustrating the fact that the paired-depolarization protocol used here induces an NMDA-dependent LTP. In the absence of APV, pairing currents from 0 to $4 \mathrm{nA}$ with orthodromic stimuli (only $0,1,2,3$, and $4 \mathrm{nA}$ shown here) produced LTP (left), whereas in different slices from the same animals LTP could not be induced in the presence of the NMDA antagonist APV (right). (Shaded bars) Adult; (solid bars) old.

9-month-old rats; $n=4$ 25-month-old rats), pairing of the orthodromic stimulus with current injection in the absence of APV produced significant LTP $[F(4,35)=28.43, P<0.0001]$, whereas in the presence of APV no significant LTP was induced $[F(4,35)=0.634, P=0.642]$. Consistent with data reported above, no significant age differences in LTP induction by this method were observed. Data for the EPSP slope following the 1-, 2-, 3-, and 4-nA current levels are shown in Figure 6B, although the current ejection paradigm used was identical to the original experiment.

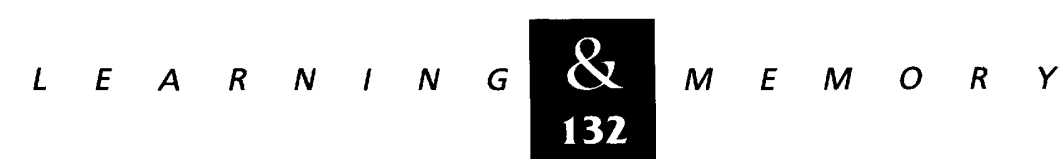




\section{CORRELATION BETWEEN BEHAVIOR AND ELECTROPHYSIOLOGICAL RESULTS}

Given that there was a statistically significant difference between the younger rats and the older age group in the size of the EPSP elicited following a fixed intensity, this variable was used to correlate with the spatial behavioral measure. The relationship between the animals' performance (CIPL) during the last block of spatial trials and the evoked EPSP amplitude in hippocampal slices derived from these rats is shown in Figure 7. A significant overall correlation for CIPL versus EPSP amplitude was observed $[20 \mu \mathrm{A}: F(1,88)=4.041$, $P<0.0001 ; 60 \mu \mathrm{A}: F(1,88)=14.05, P<0.0003]$; however, within age groups this relationship only reached statistical significance post hoc for the old rats, at both the $20-\mu \mathrm{A}$ intensity (pup: $F(1,28)=$ 4.04, $P=0.054$; adult: $F(1,28)=0.52, P=0.478$; old: $F(1,28)=9.91, P=0.0039]$ and the $60 \mu \mathrm{A}$ intensity (pup: $F(1,28)=3.82, P=0.061$; adult: $F(1,28)=0.01, P=0.926$; old: $F(1,28)=11.09$, $P=0.0024]$. Consistent with observations made between young and old animals at the perforant path-granule cell synapse (Barnes 1979), no significant correlations (overall or within age groups ) were found between spatial behavior and the magnitude of LTP induced at the Schaffer collateral-CA1 pyramidal cell synapse $[F(1,88)=$ $0.047, P=0.830]$.

\section{Discussion}

The major finding of this study is that, when the paired-depolarization method of LTP induction is used, no age differences in threshold for LTP induction or in absolute magnitude of LTP were found from 1 to 28 months of age in the male F-344 rat. Because of the large numbers of animals used in each age group ( $n=30$ in each of three groups), it is not likely that this result arose because of lack of power to detect a meaningful effect. Thus, if there is an effect of age in the experimental induction of LTP in the F-344 rat, then it is likely to be attributable to factors that arise before the involvement of the NMDA receptor. These results are inconsistent with the hypothesis that NMDA receptor-mediated events in CA1 are defective in old animals. Although alternatives certainly could be proposed, the data are consistent with the hypothesis that there are fewer Schaffer collateral synaptic contacts (structural or func-

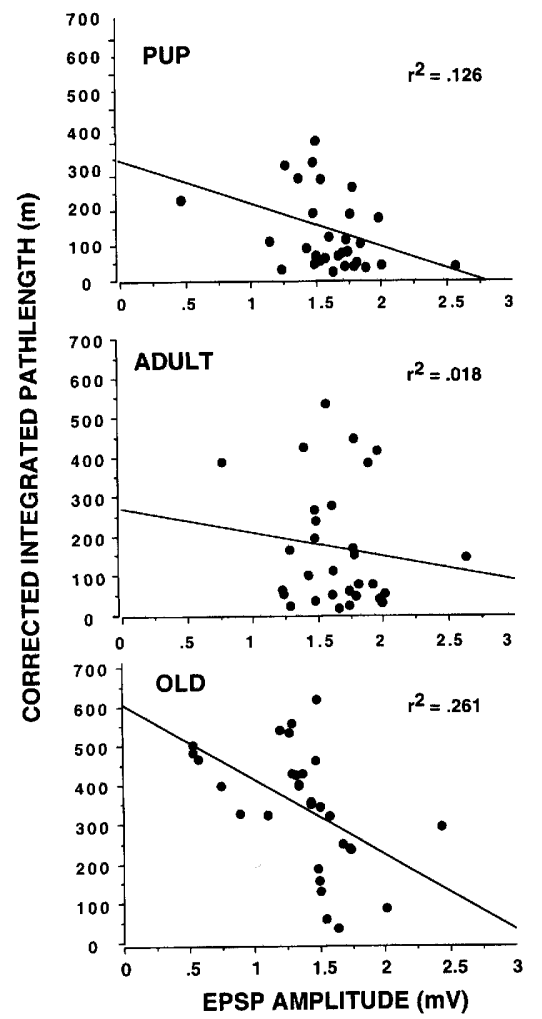

Figure 7: Spatial behavior score compared with the amplitude of the intracellularly recorded EPSP elicited at a fixed intensity ( $20 \mu \mathrm{A}$ for this example). Although there was a negative regression in each age group (i.e., rats with larger EPSPs tended to show better spatial performance, or shorter path lengths) and a significant effect when all rats were pooled, the relationship between spatial behavior and synaptic response was only statistically significant within the group of old rats.

tional) in old rats and that the failure of LTP induction using near-threshold stimulation parameters (Deupree et al. 1991, 1993; Moore et al. 1993 ) could be attributable to insufficient synaptic convergence in the old rats. If there are fewer functional synapses in CA1, then the implication for cognition in old animals includes the possibility that the mechanisms are in place for normal learning, as long as conditions for sufficient convergence can be set up. It is equally possible, however, that under normal conditions, there is such a cooperativity failure and that this may contribute to the observed memory deficits.

Overall, the electrophysiological data collected in this large sample of rats is consistent with other experiments that have demonstrated preservation of basic biophysical properties of old pyramidal cells, such as resting potential and input re- 


\section{Barnes et al.}

sistance (Barnes 1994). Also consistent with several earlier reports, we observed a decrease in the size of the Schaffer collateral-CA1 synaptic response in old rats (Landfield et al. 1986; Barnes et al. 1992; Bauman et al. 1992; Gribkoff and Bauman 1992; Rao et al. 1993; Papatheodoropoulus and Kostopoulos 1996) and a paradoxical lowering of the threshold for action potential generation (i.e., greater excitability) in pyramidal cells of old rats (Landfield et al. 1986; Barnes et al. 1987; Kerr et al. 1991; Papatheodoropoulos and Kostopoulos 1996). The present experiment is inconsistent, however, with reports of changed electrotonic properties of pyramidal cell dendrites in old rats (Turner and Deupree 1991). Other studies have also failed to observe altered electrotonic properties in hippocampal cells (Barnes and McNaughton 1980a; Foster et al. 1991; Barnes et al. 1992). If there were an increase in electrotonic length in the cells of the old rats in the present study, the active synapses would have been electrically more remote from the current injection and depolarization of the soma. Such conditions would have increased the likelihood of observing an apparent LTP induction threshold difference using the paired-depolarization method. This was not observed.

Finally, it is of interest that the smaller synaptic response in old rats, which may be attributed to synapse sparsity, was significantly related to spatial learning ability in the old rats. This observation encourages the application of therapeutic approaches that might ameliorate this relatively easily observed neurobiological marker of aging (e.g., Cohen and Müller 1992; Castorina et al. 1993; Pittaluga et al. 1993).

\section{Acknowledgments}

We thank J. Shen for assistance with part of the behavioral testing and $\mathrm{E}$. Rosenzweig for helpful comments on the manuscript. The work was supported by grants AG03376 and $\mathrm{MH} 01227$.

The publication costs of this article were defrayed in part by payment of page charges. This article must therefore be hereby marked "advertisement" in accordance with 18 USC section 1734 solely to indicate this fact.

\section{References}

Albert, M.S. 1988. General issues in geriatric neuropsychology. In Ceriatric neuropsychology (ed. M.S. Albert and M.B. Boss), pp. 3-10. Guilford Press, New York, NY.

Barnes, C.A. 1979. Memory deficits associated with senescence: A neurophysiological and behavioral study in the rat. J. Comp. Physiol. Psychol. 931: 74-104.

1990. Animal models of age-related cognitive decline. In Handbook of neuropsychology (ed. F. Boller and J. Grafman), pp. 169-196. Elsevier Science Publishers, Amsterdam, The Netherlands.

1994. Normal aging: Regional specific changes in hippocampal synaptic transmission. Trends Neurosci. 17: 13-18.

1995. Involvement of LTP in memory: Are we "searching under the street light?" Neuron 15: 751-754.

Barnes, C.A. and B.L. McNaughton. 1979.

Neurophysiological comparison of dendritic cable properties in adolescent, middle-aged, and senescent rats. Exp. Brain Res. 5: 195-206.

1980a. Physiological compensation for loss of afferent synapses in rat hippocampal granule cells during senescence. J. Physiol. 309: 473-485.

1980b. Spatial memory and hippocampal synaptic plasticity in middle-aged and senescent rats. In Psychobiology of aging: Problems and perspectives (ed. D. Stein), pp. 253-272. Elsevier Press, New York, NY.

1985. An age comparison of the rates of acquisition and forgetting of spatial information in relation to long-term enhancement of hippocampal synapses. Behav. Neurosci. 99: 1040-1048.

Barnes, C.A., G. Rao, and B.L. McNaughton. 1987. Increased electrotonic coupling in aged rat hippocampus: A possible mechanism for cellular excitability changes. J. Comp. Neurol. 259: 549-558.

Barnes, C.A., G. Rao, T.C. Foster, and B.L. McNaughton. 1992. Region-specific age effects on AMPA sensitivity: Electrophysiological evidence for loss of synaptic contacts in hippocampal field CA1. Hippocampus 2: 457-468.

Barnes, C.A., A. Treves, G. Rao, and J. Shen. 1994 Electrophysiological markers of cognitive aging: Region specificity and computational consequences. Semin. Neurosci. 6: 359-367.

Baudry, M., D.S. Arst, and G. Lynch. 1981. Increased [3H] glutamate binding in aged rats. Brain Res. 223: 195-198.

Bauman, L.A., C.D. Mahle, C.G. Boissard, and V.K. Gribkoff. 1992. Age-dependence of effects of A1 adenosine receptor antagonism in rat hippocampal slices. I. Neurophysiol. 68: 629-638.

Baxter, M.G., T.H. Lanthorn, K.M. Frick, S. Golski, R.Q. Wan, and D.S. Olton. 1994. D-cycloserine, a novel cognitive enhancer, improves spatial memory in aged rats. Neurobiol. Aging 15: 207-213.

Bliss, T.V.P. and T. Lømo. 1973. Long-lasting potentiation of 
synaptic transmission in the dentate area of the unanaesthetised rabbit following stimulation of perforant path. J. Physiol. 232: 357-374.

Bonhaus, D., W. Perry, and J. McNamara. 1990. Decreased density, but not number, of N-methyl-D-aspartate, glycine and phencyclidine binding sites in hippocampus of senescent rats. Brain Res. 532: $82-86$.

Casoli, T., C. Spagna, P. Fattoretti, R. Gesuita, and C. Bertoni-Freddari. 1996. Neuronal plasticity in aging: A quantitative immunohistochemical study of GAP-43 distribution in discrete regions of the brain. Brain Res. 714: $111-117$.

Castorina, M., A.M. Ambrosini, A. Giuliani, L. Pacifici, and L. Angelucci. 1993. A cluster analysis study of acetyl-L-carnitine effect on NMDA receptors in aging. Exp. Gerontol. 28: 537-548.

Cimino, M., P. Mariani, S. Colombo, F. Cattebeni, and J. Meldolesi. 1993. [3H]-CGP 39653 mapping of glutamatergic $\mathrm{N}$-methyl-D-aspartate in the brain of aged rats. Neurosci. Res. Commun. 12: 31-39.

Clark, A., K. Magnusson, and C. Cotman. 1992. Invitro autoradiography of hippocampal excitatory amino acid binding in aged Fischer 344 rats: Relationship to performance on the Morris water maze. Behav. Neurosci. 106: 324-335.

Cohen, N.J. and H. Eichenbaum. 1993. Memory, amnesia, and the hippocampal system. MIT Press, Cambridge, MA.

Cohen, S.A. and W.E. Müller. 1992. Age-related alterations of NMDA-receptor properties in the mouse forebrain: Partial restoration by chronic phosphatidylserine treatment. Brain Res. 584: 174-180.

Collingridge, G.L. 1987. Synaptic plasticity. The role of NMDA receptors in learning and memory. Nature 330: 604-605.

Collingridge, G.L., S.J. Kehl, and H. McLennan. 1983. The antagonism of amino acid-induced excitation of rat hippocampal CA1 neurons in vitro. J. Physiol. 334: 19-31.

Craik, F.I.M., N.D. Anderson, S.A. Kerr, and K.Z.H. Li. 1995. Memory changes in normal aging. In Handbook of memory disorders (ed. A.D. Baddeley, B.A. Wilson, and F.N. Watts), pp. 211-241. Wiley, New York, NY.

Davis, S., A.L. Markowska, G.L. Wenk, and C.A. Barnes. 1993. Acetyl-L-carnitine: Behavioral, electrophysiological, and neurochemical effects. Neurobiol. Aging 14: 107-115.

de Toledo-Morrell, L., Y. Geinisman, and F. Morrell. 1988. Age-dependent alterations in hippocampal synaptic plasticity: Relation to memory disorders. Neurobiol. Aging 9: 581-590.

Deupree, D.L., D.A. Turner, and C.L. Watter. 1991. Spatial performance correlates with in vitro potentiation in young and aged Fischer 344 rats. Brain Res. 554: 1-9.
Deupree, D.L., J. Bradley, and D.A. Turner. 1993. Age-related alterations in potentiation in the CA1 region in F344 rats. Neurobiol. Aging 14: 249-258.

Fiore, L. and L. Rampello. 1989. L-acetylcarnitine attenuates the age-dependent decrease of NMDA-sensitive glutamate receptors in rat hippocampus. Acta Neurologica 11: $346-350$.

Foster, T.C., C.A. Barnes, G. Rao, and B.L. McNaughton. 1991. Increase in perforant path quantal size in aged F-344 rats. Neurobiol. Aging 12: 441-448.

Gallagher, M., E. Bostock, and R. King. 1985. Effects of opiate antagonists on spatial memory in young and aged rats. Behav. Neural Biol. 44: 374-385.

Gallagher, M., R.D. Burwell, M.H. Kodsi, M. McKinney, S. Southerland, L. Vella-Rountree, and M.H. Lewis. 1990. Markers for biogenic amines in the aged rat brain:

Relationship to decline in spatial learning ability. Neurobiol. Aging 11: 507-514.

Gallagher, M., R. Burwell, and M. Burchinal. 1993. Severity of spatial learning impairment in aging: Development of a learning index for performance in the Morris water maze. Behav. Neurosci. 107: 618-626.

Geinisman, Y., L. de Toledo-Morrell, and F. Morrell. 1986a. Aged rats need a preserved complement of perforated axospinous synapses per hippocampal neuron to maintain good spatial memory. Brain Res. 398: 266-275.

1986b. Loss of perforated synapses in the dentate gyrus: Morphological substrate of memory deficit in aged rats. Proc. Nat. Acad. Sci. 83: 3027-3031.

Geinisman, Y., L. de Toledo-Morrell, F. Morrell, I.S. Persina, and M. Rossi. 1992. Structural synaptic plasticity associated with the induction of long-term potentiation is preserved in the dentate gyrus of aged rats. Hippocampus 2: 445-456.

Geinisman, Y., L. de Toledo-Morrell, F. Morrell, and R.E. Heller. 1995. Hippocampal markers of age-related memory dysfunction: Behavioral, electrophysiological and morphological perspectives. Prog. Neurobiol. 45: 223-252.

Gribkoff, V.K. and L.A. Bauman. 1992. Endogenous adenosine contributes to hypoxic synaptic depression in hippocampus from young and aged rats. J. Neurophysiol. 68: $620-628$.

Gustafsson, B. and H. Wigström. 1986. Hippocampal long-lasting potentiation produced by pairing single volleys and brief conditioning tetani evoked in separate afferents. /. Neurosci. 6: 1575-1582.

Gustafsson, B., W. Wigström, W. Abraham, and Y.-Y. Huang. 1987. Long-term potentiation in the hippocampus using depolarizing current pulses as the conditioning stimulus to single volley synaptic potentials. J. Neurosci. 7: 774-780.

Haas, H., B. Schaerer, and M. Vosmansky. 1979. A simple

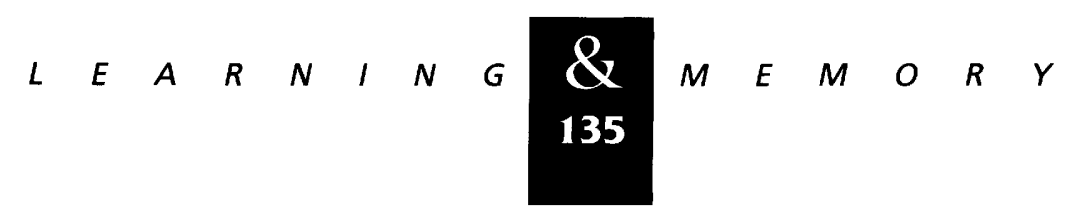




\section{Barnes et al.}

perfusion chamber for the study of nervous tissue slices in vitro. I. Neurosci. Methods 1: 323-325.

Hori, N., I. Hirotsu, P.J. Davis, and D.O. Carpenter. 1992. Long-term potentiation is lost in aged rats but preserved by calorie restriction. Neuroreport 3: 1085-1088.

Ingram, D.K., P.Garofalo, E.L. Spangler, C.R. Mantione, I. Odano, and E.D. London. 1992. Reduced density of NMDA receptors and increased sensitivity to dizocilpine-induced learning impairment in aged rats. Brain Res. 580: 273-280.

Ingram, D.K., A. Shimada, A. Mukhin, and E.D. London. 1996. Evaluating the glutamate hypothesis of geriatric memory impairment: Focus on hippocampal NMDA receptors. Perspectives Brain Aging Res. 1: 30-35.

Kerr, D.S., L.W. Campbell, S.-Y. Hao, and P.W. Landfield. 1989. Corticosteroid modulation of hippocampal potentials: Increased effect with aging. Science 245: 1505-1509.

Kerr, D.S., L.W. Campbell, M.D. Applegate, A. Brodish, and P.W. Landfield. 1991. Chronic stress-induced acceleration of electrophysiologic and morphometric biomarkers of hippocampal aging. J. Neurosci. 11: 1316-1326.

Kito, S., R. Miyoshi, and T. Nomoto. 1990. Influence of age on NMDA receptor complex in rat brain studied by in vitro autoradiography. I. Histochem. Cytochem. 38: 1725-1731.

Kusztos, R.D., D.K. Ingram, E.L. Spangler, and E.D. London. 1996. Effects of aging and chronic nimodipine on hippocampal binding of $\left[{ }^{3} \mathrm{H}\right] \mathrm{CGS}$ 19755. Neurobiol. Aging 17: $453-457$

Landfield, P.W. 1988. Hippocampal neurobiological mechanisms of age-related memory dysfunction. Neurobiol. Aging 9: 571-579.

Landfield, P.W. and G. Lynch. 1977. Impaired monosynaptic potentiation in in vitro hippocampal slices from aged, memory deficient rats. J. Gerontol. 32: 523-533.

Landfield, P.W. and T.A. Pitler. 1984. Prolonged $\mathrm{Ca}^{2+}$-dependent afterhyperpolarizations in hippocampal neurons of aged rats. Science 226: 1089-1092.

Landfield, P.W., G. Rose, L. Sandles, T.C. Wohlstadter, and G. Lynch. 1977. Patterns of astroglial hypertrophy and neuronal degeneration in the hippocampus of aged, memory-deficient rats. J. Gerontol. 32: 3-12.

Landfield, P.W., J.L. McGaugh, and G. Lynch. 1978. Impaired synaptic potentiation processes in the hippocampus of aged, memory-deficient rats. Brain Res. 150: 85-101.

Landfield, P.W., T.A. Pitler, and M.D. Applegate. 1986. The effects of high $\mathrm{Mg}^{2+}$-to-Ca ${ }^{2+}$ ratios on frequency potentiation in hippocampal slices of young and aged rats. I. Neurophysiol. 56: 797-811.

Lin, J.H., L.J. Way, and P.W. Gean. 1993. Pairing of preand postsynaptic activities in hippocampal CA1 neurons induces long-term modifications of NMDA receptor-mediated synaptic potential. Brain Res. 603: 117-120.
Lindner, M.D. and V.K. Gribkoff. 1992. Relationship between performance in the Morris water task, visual acuity, and thermoregulatory function in aged F-344 rats. Behav. Brain Res. 45: 45-55.

Lupica, C.R., W.R. Proctor, and T.V. Dunwiddie. 1992. Presynaptic inhibition of excitatory synaptic transmission by adenosine in rat hippocampus: Analysis of unitary EPSP variance measured by whole-cell recording. I. Neurosci. 12: $3753-3764$.

Lynch, M.A. and K.L. Voss. 1994. Membrane arachidonic acid concentration correlates with age and induction of long-term potentiation in the dentate gyrus of the rat. Eur. J. Neurosci. 6: 1008-1014.

McNaughton, B.L., R.M. Douglas, and G.V. Goddard. 1978. Synaptic enhancement in fascia dentata: Cooperativity among coactive afferents. Brain Res. 157: 277-293.

McNaughton, B.L., C.A. Barnes, and P. Anderson. 1981. Synaptic efficacy and EPSP summation in granule cells of rat fascia dentata studied in vitro. J. Neurophysiol. 46: 952-966.

Magnusson, K.R. 1996. Glycine enhances binding to the NMDA receptor complex in aged mice, but does not correct the aging change. I. Gerontol. 51A: B141-B147.

Magnusson, K.R. and C.W. Cotman. 1993. Effects of aging on NMDA and MK801 binding sites in mice. Brain Res. 604: 334-337.

Malenka, R.C. 1991. Postsynaptic factors control the duration of synaptic enhancement in area CA1 of the hippocampus. Neuron 6: 53-60.

Meaney, M.J., D.H. Aitken, C. van Berkel, S. Bhatnagar, and R.M. Sapolsky. 1988. Effect of neonatal handling on age-related impairments associated with the hippocampus. Science 239: 766-768.

Moore, C.I., M.D. Browning, and G.M. Rose. 1993. Hippocampal plasticity induced by primed burst, but not long-term potentiation, stimulation is impaired in area CA1 of aged Fischer 334 rats. Hippocampus 3: 57-66.

Moyer, J.R., Jr., L.T. Thompson, J.P. Black, and J.F. Disterhoft. 1992. Nimodipine increases excitability of rabbit CA1 pyramidal neurons in an age-and concentration-dependent manner. J. Neurophysiol. 68: 2100-2109.

Müller, W.E., S. Stoll, K. Scheuer, and A. Meichelböck. 1994. The function of the NMDA-receptor during normal brain aging. J. Neural Transmission 44: 145-158.

Ogawa, N., K. Mizukawa, K.M. Haba, M. Asanuma, and A. Mori. 1992. Effects of chronic bifemelane hydrochloride administration on receptors for $\mathrm{N}$-methyl-D-aspartate in the aged rat brain. Neurochem. Res. 17: 687-691.

O'Keefe, J. and L. Nadel. 1978. The hippocampus as a cognitive map. Clarendon Press, Oxford, UK.

Papatheodoropoulos, C. and G. Kostopoulos. 1996. Age-related changes in excitability and recurrent inhibition in the rat CA1 hippocampal region. Eur. I. Neurosci. 8: $510-520$. 
Pelleymounter, M.A., G. Beatty, and M. Gallagher. 1990. Hippocampal $3 \mathrm{H}-\mathrm{CPP}$ binding and spatial learning deficits in aged rats. Psychobiology 18: 298-304.

Petersen, R.C. 1995. Normal aging, mild cognitive impairment, and early Alzheimer's disease. The Neurologist 1: 326-344.

Pittaluga, A., E. Fedele, C. Risiglione, and M. Raiteri. 1993. Age-related decreases of the NMDA receptor-mediated noradrenaline release in rat hippocampus and partial restoration by D-cycloserine. Eur. I. Pharmacol. 231: 129-134.

Potier, B., O. Rascol, F. Jazat, Y. Lamour, and P. Dutar. 1992. Alterations in the properties of hippocampal pyramidal neurons in the aged rat. Neuroscience 48: 793-806.

Potier, B., Y. Lamour, and P. Dutar. 1993. Age-related alterations in the properties of hippocampal pyramidal neurons among rat strains. Neurobiol. Aging 14: 17-25.

Rao, G., C.A. Barnes, B.L. McNaughton, J. Shen, and T.W. Abel. 1993. Age-related decrease in the NMDA-mediated EPSP in CA1. Soc. Neurosci. Abstr. 19: 794.

Rao, G., J. Shen, C.A. Barnes, and B.L. McNaughton. 1995. Preserved LTP induction in CA1 of aged F-344 rats. Soc. Neurosci. Abstr. 21: 940.

Rao, G., G.D. Stevenson, C.A. Barnes, B.L. McNaughton, and K.L. Weaver. 1996. Age-related decrease in the Schaffer collateral evoked EPSP in chronically implanted F-344 rats. Soc. Neurosci. Abstr. 22: (in press).

Rapp, P.R. and D.G. Amaral. 1992. Individual differences in the cognitive and neurobiological consequences of normal aging. Trends Neurosci. 15: 340-345.

Reynolds, J.N. and P.L. Carlen. 1989. Diminished calcium currents in aged hippocampal dentate gyrus granule neurones. Brain Res. 479: 384-390.

Scheff, S.W., K.J. Anderson, and S.T. DeKosky. 1985. Strain comparison of synaptic density in hippocampal CA1 of aged rats. Neurobiol. Aging 6: 29-34.

Scheuer, K., S. Stoll, U. Paschke, R. Weigel, and W.E. Müller. 1995. N-methyl-D-aspartate receptor density and membrane fluidity as possible determinants of the decline of passive avoidance performance in aging. Pharmacol. Biochem. Behav. 50: 65-70.

Segal, M. 1982. Changes in neurotransmitter actions in the aged rat hippocampus. Neurobiol. Aging 3: 121-124.

Shahi, K. and M. Baudry. 1993. Glycine-induced changes in synaptic efficacy in hippocampal slices involve changes in AMPA receptors. Brain Res. 627: 261-266.

Shen, ). and C.A. Barnes. 1996. Age-related decrease in cholinergic synaptic transmission in three hippocampal subfields. Neurobiol. Aging 17: 439-451.
Shimada, A., A. Mukhin, D.K. Ingram, and E.D. London. 1996. $\mathrm{N}$-methyl-D-aspartate receptor binding in brains of rats at different ages. Neurobiol. Aging (in press).

Squire, L.R. 1992. Memory and the hippocampus: A synthesis from findings with rats, monkeys, and humans. Psychol. Rev. 99: 195-231.

Stone, T.W. 1994. Excitatory amino acids and dementia. In Anti-dementia agents (ed. C.D. Nicholson), pp. 229-249. Academic Press, New York, NY.

Straube, K.T., R.A. Deyo, J.R. Moyer, Jr., and J.F. Disterhoft. 1990. Dietary nimodipine improves associative learning in aging rabbits. Neurobiol. Aging 11: 659-661.

Tamaru, M., Y. Yoneda, K. Ogita, J. Shimizu, and Y. Nagata. 1991. Age-related decreases of the $\mathrm{N}$-methyl-D-aspartate receptor complex in the rat cerebral cortex and hippocampus. Brain Res. 542: 83-90.

Taylor, L. and W.H. Griffith. 1993. Age-related decline in cholinergic synaptic transmission in hippocampus. Neurobiol. Aging 14: 509-515.

Thibault, O. and P.W. Landfield. 1996. Increase in single L-type calcium channels in hippocampal neurons during aging. Science 272: 1017-1020.

Tielen, A.M., W.J. Mollevanger, F.H. Lopes da Silva, and C.F. Hollander. 1983. Neuronal plasticity in hippocampal slices of extremely old rats. In Aging of the brain (ed. W.H. Gispen and J. Traber), pp. 73-84. Elsevier Science Publishers, New York, NY.

Turner, D.A. and D.L. Deupree. 1991. Functional elongation of CA1 hippocampal neurons with aging in Fischer 344 rats. Neurobiol. Aging 12: 201-210.

Wenk, G.L., L.C. Walker, D.L. Price, and L.C. Cork. 1991. Loss of NMDA, but not GABA-A, binding in the brains of aged rats and monkeys. Neurobiol. Aging 12: 93-98.

Wigström, H., B. Gustafsson, Y.-Y. Huang, and W.C. Abraham. 1986. Hippocampal long-term potentiation is induced by pairing single afferent volleys with intracellularly injected depolarizing current pulses. Acta Physiol. Scand. 126: 317-319.

Worley, P.F., R.V. Bhat, J.M. Baraban, C.A. Erickson, B.L. McNaughton, and C.A. Barnes. 1993. Thresholds for synaptic activation of transciption factors in hippocampus: Correlation with long-term enhancement. I. Neurosci. 13: $4776-4786$.

Yoshioka, N. and M. Sakurai. 1995. Postsynaptic depolarization in induction of long-term potentiation in the CA1 hippocampus. Neuroreport 6: 333-336.

Zyzak, D.R., T. Otto, H. Eichenbaum, and M. Gallagher. 1995. Cognitive decline associated with normal aging in rats: A neuropsychological approach. Learn. \& Mem. 2: 1-16.

Received July 3, 1996; accepted in revised form August 9, 1996.

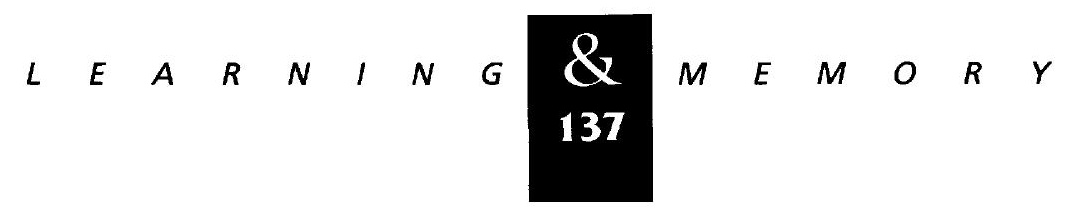




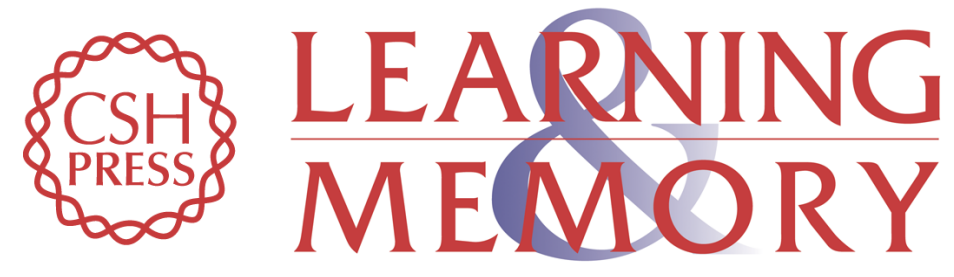

\section{Functional integrity of NMDA-dependent LTP induction mechanisms across the lifespan of F-344 rats.}

C A Barnes, G Rao and B L McNaughton

Learn. Mem. 1996, 3:

References This article cites 91 articles, 10 of which can be accessed free at: http://learnmem.cshlp.org/content/3/2-3/124.full.html\#ref-list-1

License

Email Alerting Receive free email alerts when new articles cite this article - sign up in the box at the Service top right corner of the article or click here. 